\title{
Acute and Chronic Dopamine Dynamics in a Nonhuman Primate Model of Recreational Cocaine Use
}

\author{
Charles W. Bradberry \\ Departments of Psychiatry and Laboratory Medicine, West Haven Veterans Administration Hospital and Yale University \\ School of Medicine, West Haven, Connecticut 06516
}

\begin{abstract}
Using a model of recreational cocaine consumption, we have determined in four rhesus monkeys the impact of selfadministered cocaine on mesolimbic and sensorimotor striatal dopaminergic neurotransmission. The effects of cocaine repeated within a self-administration session and across multiple sessions over a 6 month period were determined by the use of fixed-ratio self-administration and microdialysis procedures. The exposure to cocaine was modest, with at most two $0.5 \mathrm{mg} / \mathrm{kg}$ infusions permitted in each weekly session. Within a cocaine self-administration session, acute tolerance to the ability of cocaine to elevate extracellular striatal dopamine was observed. Over a period of 6 months of repeated self-administration, there was a significant increase in the impact of a fixed dose on extracellular dopamine, indicating that neurochemical sensitization to the effects of self-administered cocaine occurs in pri-
\end{abstract}

mates. A pronounced dopaminergic response to noncontingent cocaine was also observed, with no increases in extracellular dopamine in response to an unexpected saline substitution, indicating that the neurochemical response to self-administered cocaine is primarily caused by direct pharmacological effects of the drug rather than by conditioning to external environmental cues. These results highlight the contrast in time-dependent changes in neurochemical responsiveness to cocaine, depending on whether within-session or between-session comparisons are made. They also demonstrate that recreational levels of cocaine consumption can result in neurochemical sensitization, an enduring change in brain function that may contribute to addiction.

Key words: dependence; striatum; reward; relapse; psychostimulant; accumbens
Dopamine (DA) neurotransmission is believed to play an essential role in cocaine reward (Roberts et al., 1977; Ritz et al., 1987; Wise and Bozarth, 1987; Volkow et al., 1997). The neuroadaptive process in which the dopaminergic response to cocaine sensitizes after chronic exposure has been proposed to cause excessive incentive salience to be attributed to the act of drug taking and to stimuli associated with drug taking, thereby contributing to addiction (Robinson and Berridge, 1993). Although animal models of drug use investigating the impact of cocaine exposure on dopaminergic function generally involve high-dose, frequent (e.g., daily) exposure, human patterns of cocaine consumption do not generally begin as compulsive, high-dose bingeing. Rather, what begins as recreational use (e.g., on weekends) gradually progresses over time to become the focus of a user's energy and attention.

The goal of the present study was to develop and exploit a nonhuman primate self-administration model permitting in vivo measurements of extracellular dopamine over a 6 month course of "moderate" chronic cocaine exposure mimicking human recreational consumption. Because there are considerable inherent differences between rodent and primate dopaminergic systems (Berger et al., 1991) and a greater similarity in brain metabolic responses to cocaine between human and nonhuman primates (London et al., 1990; Pearlson et al., 1993), it is important that studies be done in primates to verify phenomena, such as sensitization, that have far-reaching implications for the etiology of drug addiction.

The questions about the effects of cocaine on extracellular mesolimbic DA addressed in the present study were as follows: (1)

\footnotetext{
Received May 12, 2000; revised June 28, 2000; accepted July 6, 2000.

This work was supported by National Institutes of Health Grants DA 08073, DA 04060, and DA 10331 and by the Yale-Veterans Administration Alcoholism Research Center. The excellent technical assistance of Susan Rubino, Christopher Baccei, Rita Barrett-Larimore, Shawna Ellis, and Cindy Rodriguez is also gratefully acknowledged.

Correspondence should be addressed to Dr. Charles W. Bradberry, Departments of Psychiatry and Laboratory Medicine, West Haven Veterans Administration Hospital and Yale University School of Medicine, WHVA/116A2, 950 Campbell Avenue, West Haven, CT 06516. E-mail: charles.bradberry@yale.edu.

Copyright (C) 2000 Society for Neuroscience 0270-6474/00/207109-07\$15.00/0
}

How do they change after repeated self-administration within a session? (2) How do they change with repeated exposure across a number of sessions? The first question addresses a potential mechanism underlying subjective reports of tolerance after repeated administration in humans, a phenomenon that may contribute to repeated self-dosing of increasing amounts in an attempt to maintain the desired effect (Jaffe, 1990). The second question relates to whether a neurochemical sensitization develops in primates, evidence of which is lacking.

The present drug administration paradigm was designed to model recreational weekend consumption in humans. This entailed a self-administration model of exposure, considered to be more naturalistic than investigator-administered models of chronic exposure, with a one session per week frequency and a low amount $(0.5$ or $1.0 \mathrm{mg} / \mathrm{kg}$ ) of cocaine consumed. Extracellular DA from the mesolimbic and sensorimotor striatum was measured during the self-administration sessions by the use of magnetic resonancedirected microdialysis methods.

\section{MATERIALS AND METHODS}

Overview of experimental design. Acute within-session tolerance of the dopaminergic response to cocaine was examined by comparing the first and second response to self-administered cocaine at $0.5 \mathrm{mg} / \mathrm{kg}$, with a $100 \mathrm{~min}$ time-out between infusions. DA levels returned to baseline between infusions, and the time into the session was controlled for by conducting some studies in which the initial infusion of cocaine was withheld until the time in the session when the second infusion would otherwise be occurring. Across-session sensitization was examined by regression of the average percent increase in DA over 10 min (after self-administration of the initial cocaine infusion) versus the week into the study. To assess in a general sense the relative contribution of conditioned responses in DA versus pharmacological effects of cocaine, DA levels after saline substitution and noncontingent cocaine were compared with those after self-administration of cocaine.

Details of behavioral procedures. Microdialysis studies were conducted in rhesus monkeys restrained in a chair and trained to self-administer cocaine intravenously. Four male animals were used. They were restrained in a chair (Primate Products, Redwood City, CA) by a collar and placed in a behavioral chamber fitted with an operant panel constructed from $1 / 4$ inch aluminum to which the chair was attached. Med-Associates (East Fairfield, VT) software and hardware were used for all inputs and outputs and data collection. Animals were initially trained to lever press for food pellets 
under fixed ratio (FR) 10 (animals M103 and M32) or FR30 (animals M47 and M49) lever response schedule of reinforcement for a minimum of 1 month, with animals exhibiting stimulus control as indicated with responding in the presence of a cue and little responding in its absence. Subsequent to food training (with no strict criteria), a catheter was placed in the internal jugular that led to a vascular access port (Access Technologies, Skokie, IL) placed midscapula (Wojnicki et al., 1994), and animals were shifted to cocaine (i.e., cocaine was now the reinforcer), with cocaine being signaled by an additional light of a different color on the operant panel. After switching to cocaine, food pellets or their cue were no longer made available. The vascular access port allows percutaneous nonstressful access to the vasculature without the need for a protective jacket and with reduced risk of infection because nothing is external to the skin. The device can be used daily for periods of time well over a year (Wojnicki et al., 1994; Glowa et al., 1995). In our laboratory, with less frequent (biweekly) use, ports have been usable for up to 2 years. Maintenance of the ports consists of a twice-weekly flushing with saline, locking with a solution that has a final concentration of $25 \%$ dextrose and $500 \mathrm{U} / \mathrm{ml}$ heparin. Animals quickly learned to lever press for cocaine under the same FR contingency used for obtaining food pellets.

Studies began at 10:00 A.M., although there was some variability $(<30$ min) between when an animal was first placed in a chair (immediately outside the home cage) and when the behavioral chamber (in a separate room) was closed, depending on how much difficulty was associated with attaching lines, etc. Animals were restrained in a chair in the behavioral chamber with a house light on for a $60-90 \mathrm{~min}$ baseline period before presentation of the visual cue, during which microdialysis samples were collected. During that time, no cue was presented, and lever pressing was recorded but had no consequence. The visual cue indicating cocaine availability was presented at the same time of day to each animal (11:30 A.M. for animals M103 and M32; 11:00 A.M. for animals M49 and M47). The visual cue was a horizontally placed pair of red and green lights and indicated that the FR response would result in an infusion of a bolus of 0.5 $\mathrm{mg} / \mathrm{kg}$ cocaine- $\mathrm{HCl}$ in $0.5 \mathrm{ml}$. The visual cue was turned off as the inf usion began at a flow rate of $16.3 \mathrm{ml} / \mathrm{min}$ over an $18 \mathrm{sec}$ period. The $0.5 \mathrm{ml}$ cocaine solution was loaded into the line between the syringe and the vascular access port, and an excess volume $(5 \mathrm{ml})$ was used to flush the cocaine dose completely into the animal, preventing the need to try and fill just the volume between the port and the catheter tip. This avoided any "priming" that would result from slightly overfilling that volume. Visual inspection of a dye solution in a mock setup indicated that the loaded solution was infused into the animal beginning $5 \mathrm{sec}$ into the infusion and was essentially completely infused by $10 \mathrm{sec}$ into the infusion. After the infusion, a $100 \mathrm{~min}$ time-out began, during which no cues were presented and lever pressing was recorded but had no consequences. After the time-out, the cue was presented again, with the second cue presentation and infusion the same as the first.

After microdialysis studies began, each animal was permitted at most one session per week during which two infusions would be available, separated by the $100 \mathrm{~min}$ time-out interval. In general, animals had a microdialysis session in which they received cocaine or had a "maintenance" cocaine self-administration session (with a single $0.5 \mathrm{mg} / \mathrm{kg}$ inf usion) each week. Animals underwent studies for at least 3 months during which both inf usions were $0.5 \mathrm{mg} / \mathrm{kg}$ cocaine, after which occasional saline substitutions or sessions with no cue (or cocaine) presentation were conducted. This was the extent of cocaine exposure in each animal outside of the initial training with more traditional self-administration parameters (lower unit doses and more frequent inf usions permitted). Those sessions were $30 \mathrm{~min}$ in length, with one or two (consecutive) sessions in a given day. The amount of initial training each animal received was as follows: animal M103, 3 months of training with unit doses from 0.01 to $0.3 \mathrm{mg} / \mathrm{kg}$ and a total cumulative exposure over the training period of $80 \mathrm{mg} / \mathrm{kg}$; animal M32, 1 month of training with unit doses of $0.1-0.5 \mathrm{mg} / \mathrm{kg}$ and a total cumulative exposure of $6 \mathrm{mg} / \mathrm{kg}$; and animals M49 and M47, 1 week of training each with a unit dose of $0.1 \mathrm{mg} / \mathrm{kg}$ and a total cumulative exposure of $<3 \mathrm{mg} / \mathrm{kg}$. Animals were under stimulus control as indicated by response rates that increased by one to two orders of magnitude during the time of cue presentation (Bradberry et al., 2000).

When cocaine was administered noncontingently, it was infused at the usual times into the session but without any predictive visual cues or the auditory cue of the infusion pump. Studies in which saline was substituted for cocaine were conducted in exactly the same manner as those in which cocaine was administered, with the same visual cue presentation and FR response triggering the infusion pump with its associated sound.

Microdialysis guide cannulae and probes. Details of the microdialysis procedures have been published (Bradberry et al., 2000). Probes were put in place the day before the experiment either under light ketamine anesthesia $(15 \mathrm{mg} / \mathrm{kg})$ for animals M103 and M32 or without any ketamine by the use of a head-bolting procedure for animals M47 and M49. After the probe is slowly lowered, a protective molded plastic cap was put in place. On the study day, animals were restrained in the chair, the cap was removed, and inlet and outlet lines were attached to the probe. Probe placements were in sites in which a probe had not been placed previously. There was usually just one probe in place, although occasionally two were placed. No apparent difference was ever noted between studies in which two probes were in place as opposed to one. Placement order varied
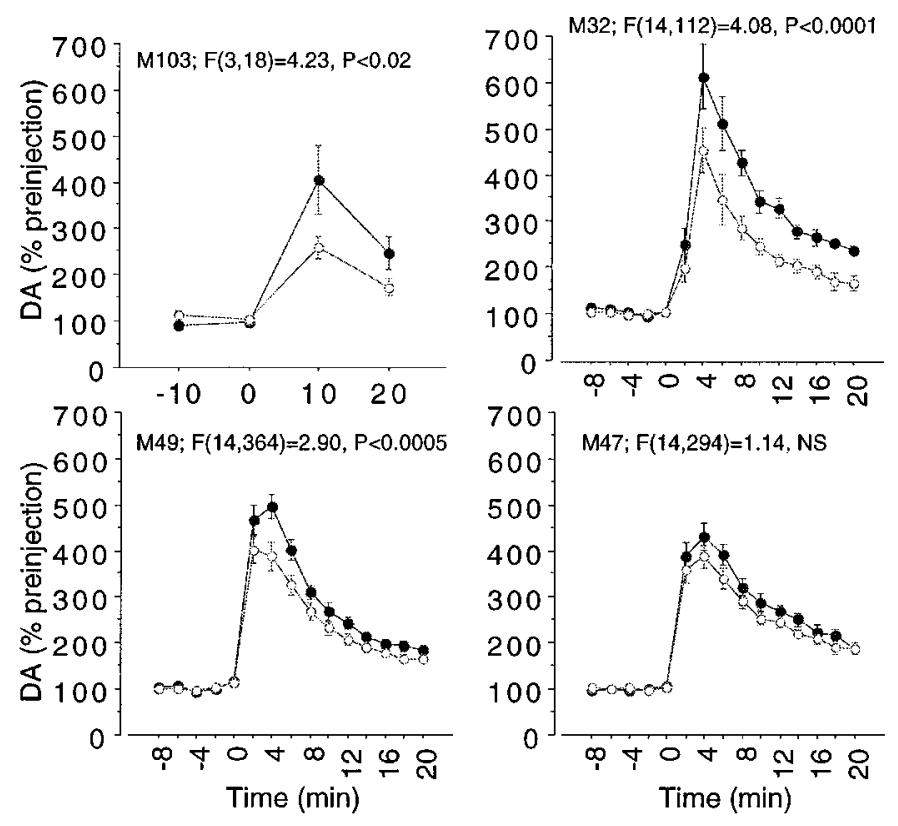

Figure 1. Within-session tolerance of the extracellular DA response to self-administered cocaine in four different rhesus monkeys (M103, M32, M49, and M47), with responses collapsed across all striatal subdivisions. Initial studies were done in animal M103 with 10 min collection times, after which, for greater temporal detail, a 2 min sampling procedure was used. For animals M49 and M47, a time offset to compensate for dead volume in the outflow lines was incorporated; thus, the temporal pattern of the dopaminergic response for them is the most accurate. Cocaine was selfadministered at $t=0$. The second self-administration occurred $100 \mathrm{~min}$ after the first in the same session. Solid circles represent the first injection; open circles represent the second injection. The number of trials is as follows: M103, $n=4$; M32, $n=5$; M49, $n=14$; M47, $n=9$.

between medial and lateral positions as well as between dorsal and ventral placements.

For the results from monkey M103 shown in Figure 1, the initial inf usion of cocaine was given when samples were being collected at 10 min intervals, with a perfusion rate set at $2 \mu \mathrm{l} / \mathrm{min}$. The second infusion was given after the perfusion rate was increased to $5 \mu \mathrm{l} / \mathrm{min}$, with samples collected at 2 min intervals. Thus, for this one animal, the second infusion was given with the microdialysis perfusion at a higher rate that was necessary for the rapid sampling. To permit a comparison, results from the second injection were averaged into $10 \mathrm{~min}$ bins. After changing the perfusion rate, there is no change in the actual mass of DA collected per unit time, making the comparison between the first and second injections for this animal valid despite the different flow rates. Additional studies (see Fig. 2) in animal M103 in which both cocaine infusions were done while the probe was being perfused at $5 \mu \mathrm{l} / \mathrm{min}$ show results equivalent to those presented in Figure 1.

Data analysis. For the acute tolerance studies, data up to 20 min after cocaine were analyzed by two-way repeated measures ANOVA of extracellular levels expressed as a percent of a precue baseline, defined as the mean of the three points preceding the cue (Robertson et al., 1991; Klitenick et al., 1992), with the order of administration as a betweengroups factor. For the chronic sensitization studies, Pearson's correlation was used to determine whether the DA response showed progressive changes over time. Simple regression was run on the mean percent increase over $10 \mathrm{~min}$ in response to the initial administration of cocaine in a session versus the week into the study. Each probe insertion was treated as an individual statistical event, as individual neuronal recordings are treated in electrophysiological studies (Schultz et al., 1993). Within each animal, responses were collapsed across all striatal regions. For evaluation of striatal regional differences, responses were collapsed across all animals.

\section{RESULTS}

\section{Acute tolerance}

In an examination of acute tolerance to repeated self-administration of cocaine, two $0.5 \mathrm{mg} / \mathrm{kg}$ inf usions of cocaine- $\mathrm{HCl}$ were made available within a session. A 100 min time-out separated the two infusions. Mean response rates after each cue presentation were very consistent as indicated in Table 1, with the FR contingency quickly reached. Figure 1 demonstrates the increase in extracellular DA (relative to the baseline preceding each injection) 
Table 1. Rates of response from the time of cue presentation to the time that contingency was reached for the self-administration of cocaine in studies presented in Figure 1

\begin{tabular}{lll} 
& $\begin{array}{l}\text { First infusion } \\
\text { (responses/sec } \pm \text { SEM) }\end{array}$ & Second inf usion \\
\hline M103 & $1.28 \pm 0.09(4)$ & $1.25 \pm 0.14(4)$ \\
M32 & $1.13 \pm 0.32(5)$ & $1.07 \pm 0.24(5)$ \\
M49 & $0.96 \pm 0.14(13)$ & $0.89 \pm 0.15(11)$ \\
M47 & $1.13 \pm 0.19(9)$ & $0.99 \pm 0.17(8)$
\end{tabular}

Numbers of observations are given in parentheses.

Table 2. Basal values of DA in microdialysates

\begin{tabular}{llll} 
& $\begin{array}{l}\text { First infusion } \\
(\mathrm{fmol} / \mu \mathrm{l} \pm \mathrm{SEM})^{a}\end{array}$ & Second infusion & First infusion late \\
\hline M103 & & $6.87 \pm 2.94(3)$ & $5.76 \pm 0.63(6)$ \\
M32 & $6.76 \pm 1.17(5)$ & $6.27 \pm 1.17(5)$ & $3.35 \pm 1.19(5)$ \\
M49 & $4.51 \pm 0.73(14)$ & $4.21 \pm 0.61(14)$ & $3.06 \pm 0.82(6)$ \\
M47 & $4.20 \pm 0.79(9)$ & $3.89 \pm 0.65(9)$ & $3.04 \pm 0.85(7)$
\end{tabular}

Numbers of observations are given in parentheses.

${ }^{a}$ Values are uncorrected for probe recovery.

after the two injections within a session in four different animals. Table 2 lists basal DA values for each group in Figure 1. For each animal (except M103 in which the first drug administration was at a different microdialysis perfusion rate, see Materials and Methods), basal levels at the time of the first and second drug infusion did not differ significantly ( $p>0.05$ ) by paired $t$ test comparison. There is a significant reduction in the magnitude of the response to the second dose in three out of the four animals by two-way repeated measures ANOVA with injection order as a betweengroups factor. Because a gradual sensitization of the dopaminergic response to cocaine was seen between sessions (see below), only paired injections (i.e., both infusions occurred in the same session) were used for the analysis so that the amount of chronic cocaine exposure was always balanced for the first and second infusions. Figure 2 shows additional studies done at a later time on animal M103 in which both infusions were done with the same microdialysis perfusion rate, with results equivalent to those shown in Figure 1. Additional studies to control for time into the session are discussed below (Fig. 3).

Comparisons between ventromedial, central, and dorsolateral striatal regions (collapsed across all animals) in the present study indicated acute tolerance in the central and ventromedial subdivisions of the mesolimbic striatum but not in the dorsolateral (sensorimotor) striatum (Fig. 4).

\section{Studies to control for the time into the session}

Studies were done in each animal in which a cocaine infusion was not made available until late in the session, at the time the second infusion would normally have occurred. For each animal, the response to an initial infusion of cocaine given late in the session was not less than the response to an initial infusion given early in the session, indicating that the reduced response to a second cocaine infusion relative to the first was not an artifact of the time into the session (Fig. 3). As can be seen, there is actually a trend in all animals (reaching significance in two) for the response to a first cocaine inf usion administered late to be larger than the response to a first cocaine infusion given early; however, these sessions were done in the latter months of the studies, and the greater response is presumably a result of a between-session sensitization of the dopaminergic response to cocaine and demonstrates why only sessions with paired infusions are presented in Figures 1 and 2.

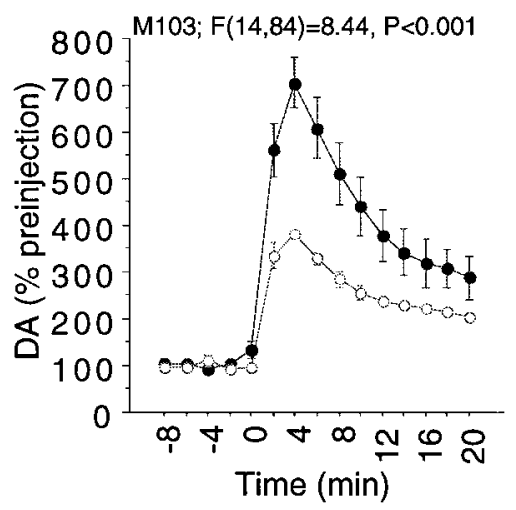

Figure 2. Within-session tolerance in animal M103 determined with the same microdialysis perfusion rate $(5 \mu \mathrm{l} / \mathrm{min})$ throughout, indicating the validity of the results for this animal in Figure 1. (Fig. 1, top left, shows data from studies with different flow rates for the first and second infusions.) Solid circles represent the first injection; open circles represent the second injection ( $n=4$ trials). Basal DA levels were as follows: first infusion, $1.42 \pm 0.53 \mathrm{fmol} / \mu \mathrm{l}$; second infusion, $1.78 \pm 0.60 \mathrm{fmol} / \mu \mathrm{l} ; t_{(6)}=-0.45, \mathrm{NS}$.
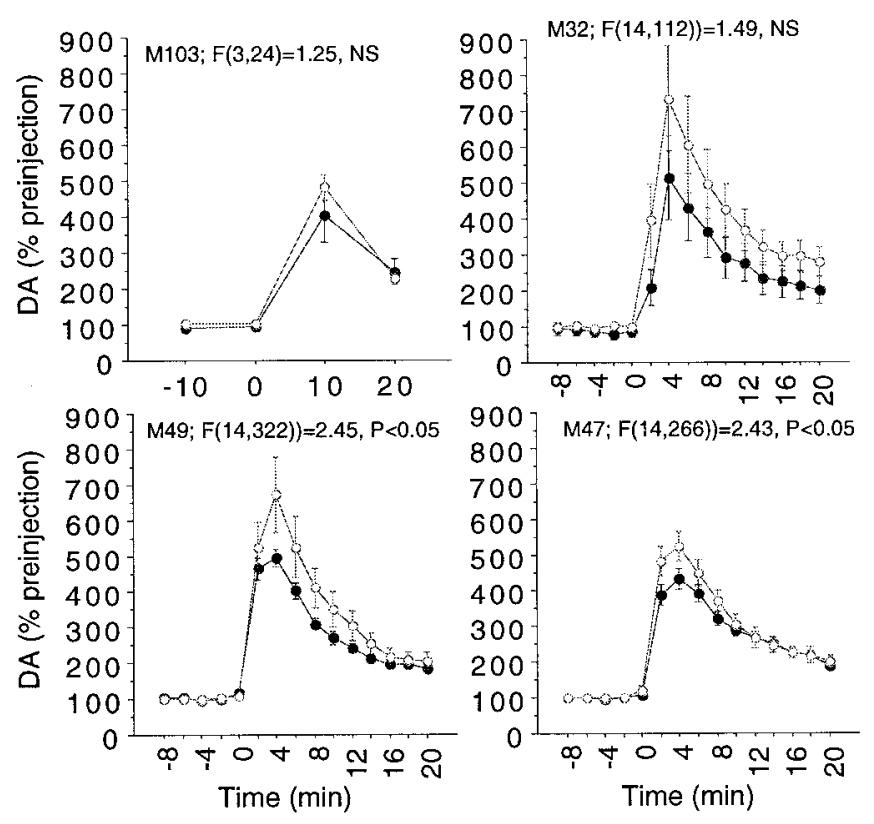

Figure 3. Self-administration of an initial infusion of cocaine late in the session (at the time the second infusion would normally occur) does not result in a diminished response, indicating that the reduced response to the second infusion shown in Figures 1 and 2 is not an artifact of the time into the session. Solid circles represent an early first infusion; open circles represent a late first infusion. The number of trials is as follows: M103, $n=$ 4 early infusions and 6 late infusions; M32, $n=6$ early inf usions and 5 late infusions; M49, $n=14$ early infusions and 11 late infusions; M47, $n=10$ early infusions and 11 late infusions.

\section{Chronic sensitization}

To determine whether there were any progressive changes in the effects of cocaine over 6 months of repeated microdialysis studies, a regression analysis of the mean percent increase (over $10 \mathrm{~min}$ ) in extracellular DA after self-administration of $0.5 \mathrm{mg} / \mathrm{kg}$ cocaine versus the week into the study was performed. Figure 5 shows the pooled data for all four animals (top left), as well as panels in which the dopaminergic response in each region is analyzed separately for changes over time. The pooled responses collapsed across all regions show a significant increase over time in the dopaminergic response to cocaine. In analyzing regions separately, it is seen that in both mesolimbic subdivisions, a progressive increase in the ability of cocaine to elevate extracellular cocaine over time occurs. However, in the dorsolateral sensorimotor subdivision, sensitization was not seen. 

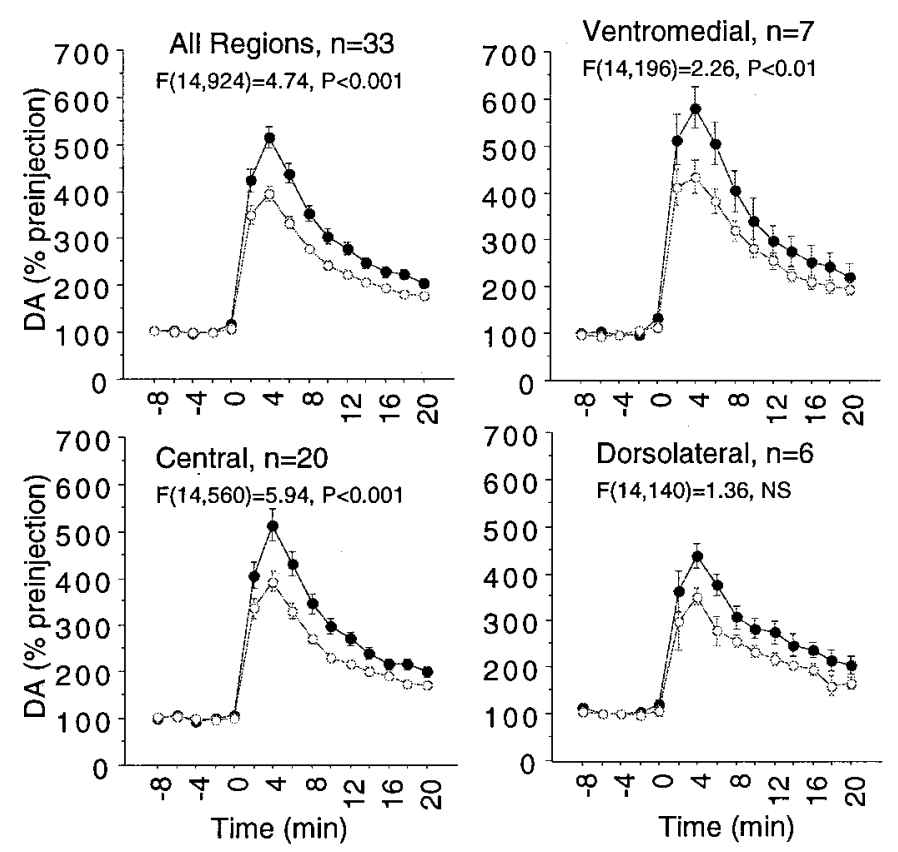

Figure 4. Subdivision of the striatum indicated no regional differences in the magnitude of tolerance seen between the first and second infusions of cocaine when responses were collapsed across animals. The number of trials is indicated on each panel.
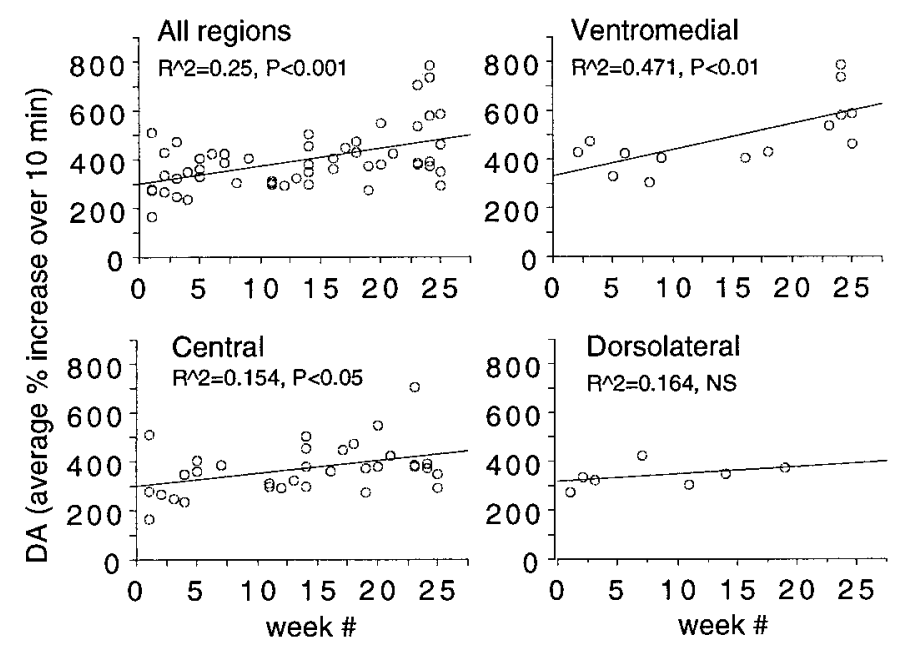

Figure 5. Progressive change in the cocaine-induced increase in extracellular DA over an extended time. Points represent the average increase relative to baseline during the $10 \mathrm{~min}$ after self-administration of an initial infusion of cocaine. Top left, Results collapsed across all animals and regions. Top right, bottom, Responses over time split by the subregion of the striatum. The two mesolimbic regions showed a significant increase in DA response over time, whereas the sensorimotor (dorsolateral) striatum did not.

In an examination of any individual differences between the animals, each animal was analyzed separately as shown in Figure 6. As can be seen, in three out of the four animals, there was a significant $(p<0.05)$ correlation between these two variables. Whether the lack of sensitization in the one animal is reflective of inherent variability in the neurochemical measurements or actual differences between individuals is difficult to specify with certainty because of the sample size.

Regression of basal DA versus time indicated no progressive changes. Regression of basal DA versus the percent $10 \mathrm{~min}$ increase showed a significant negative correlation $\left(R^{2}=0.14 ; p<\right.$ $0.05 ; n=36$ ), suggesting that basal DA was to some extent predictive of the magnitude of the response to cocaine. However, this is

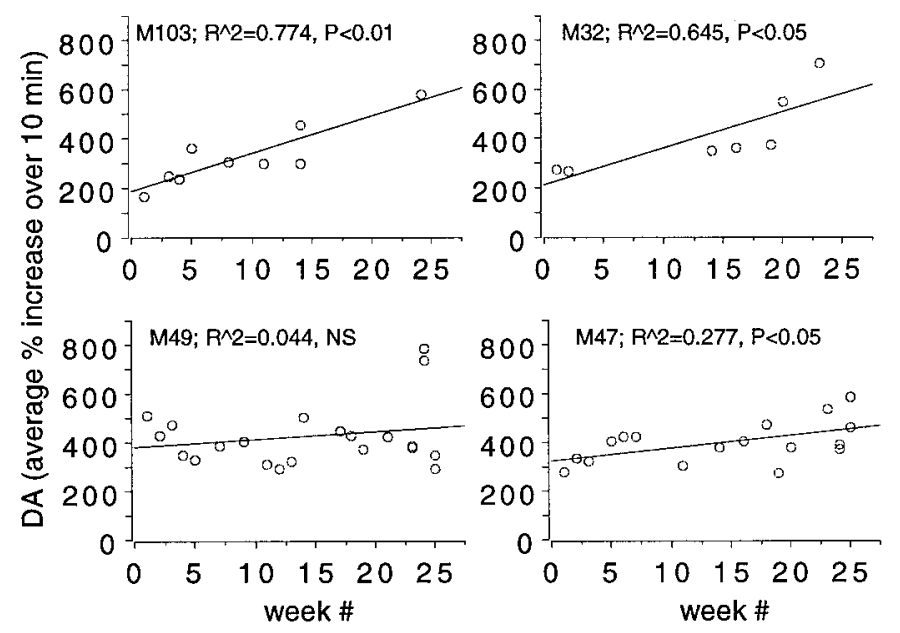

Figure 6. Changes in response to cocaine over time, determined in individual animals. Three (M103, M32, and M47) of the four animals showed a significant elevation in the effect of cocaine over time.

more likely an artifact of the lower basal DA levels in the ventromedial striatum that is also the most responsive striatal subdivision (Bradberry et al., 2000). If each region is examined separately, there was no trend toward a correlation of basal DA versus the percent $10 \mathrm{~min}$ increase.

\section{Chronic changes in behavior}

The mean response rate for lever pressing (measured from the time of cue presentation to the time that contingency was reached) did not correlate with the time into the study for monkey M103 $\left(R^{2}=\right.$ 0.27 , NS) or monkey M32 $\left(R^{2}<0.01\right.$, NS) but did for both animals M47 $\left(R^{2}=0.477 ; p<0.05\right)$ and M49 $\left(R^{2}=0.498 ; p<0.05\right)$.

\section{Dopaminergic impact of noncontingent cocaine and saline substitution}

To determine whether the dopaminergic impact observed in response to self-administered cocaine is actually a conditioned response associated with training, we administered noncontingent cocaine at the usual time within a session as the self-administered cocaine. Figure 7 demonstrates that there was a pronounced dopaminergic impact of noncontingent cocaine in each animal. Saline substitution data from Bradberry et al. (2000) are also presented in this figure, indicating no response to saline substitution (by oneway repeated measures ANOVA) with all external cues normally associated with cocaine present (i.e., the visual cue offset and the auditory cue of the infusion pump).

\section{DISCUSSION}

These results demonstrate that in a primate model of recreational cocaine use, both acute tolerance to and chronic sensitization of the impact of cocaine on extracellular striatal DA occur. The phenomena of tolerance and sensitization have been implicated in various aspects of psychostimulant dependency and relapse (Jaffe, 1990; Robinson and Berridge, 1993; Schenk and Partridge, 1997; De Vries et al., 1998).

\section{Acute tolerance}

Tolerance to the subjective effects of repeated cocaine has consistently been seen in human laboratory studies by Fischman and colleagues (Javaid et al., 1978; Foltin and Fischman, 1991, 1992; Ward et al., 1997) and others (Ambre et al., 1988; Kumor et al., 1989). This phenomenon may contribute to binge patterns of consumption (Jaffe, 1990) because a user consumes progressively larger amounts to recapture the initial high obtained with the first dose. The present results suggest that tolerance to the subjective effects of repeated cocaine could be caused by a reduced dopaminergic response to repeated cocaine. This presupposes that increased extracellular DA is a primary mediator of psychostimulant- 

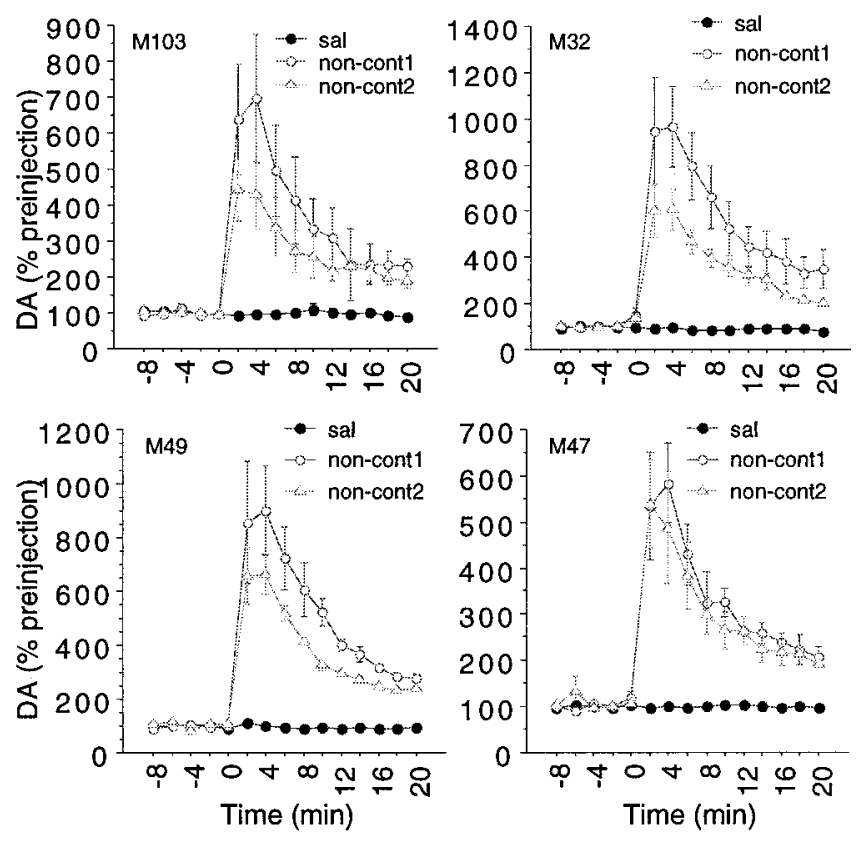

Figure 7. Dopaminergic response to noncontingent cocaine or surprise saline substitution. sal, Saline substitution; non-cont1, first noncontingent infusion; non-cont 2 , second noncontingent infusion. $n=2-4$ trials per animal for noncontingent cocaine and 4-6 trials per animal for saline substitution.

induced euphoria. However, it has been noted that there is evidence conflicting with this idea (Rothman and Glowa, 1995; Brauer et al., 1997; Berridge and Robinson, 1998). Although the present results are consistent with a dopaminergic mediation of cocaine reward, it is correlative support only.

There are clear functional subdivisions of the striatum based on anatomical connectivity (Yeterian and Van Hoesen, 1978; Russchen et al., 1985; Selemon and Goldman-Rakic, 1985; Lynd-Balta and Haber, 1994; Haber and McFarland, 1999). There is also enhanced responsivity of the mesolimbic striatum to cocaine as indicated by metabolic studies (Lyons et al., 1996) and to noncocaine rewards as indicated in electrophysiological studies (Apicella et al., 1991). We have made comparisons previously between striatal areas subdivided into sensorimotor function (dorsolateral striatum) and mesolimbic function [ventromedial striatum, receiving orbital prefrontal projections; central striatum, receiving dorsolateral prefrontal projections (Haber and McFarland, 1999)]. Those studies demonstrated enhanced responsiveness to cocaine in the ventromedial striatum (Bradberry et al., 2000). Comparisons between striatal regions indicated acute tolerance in the central and ventromedial subdivisions of the mesolimbic striatum but not in the dorsolateral sensorimotor striatum (Fig. 4). However, the lack of effect in the dorsolateral region could be caused by reduced statistical power associated with fewer trials. There did not appear to be large differences in the tolerance effect between the regions.

Most previous animal studies of tolerance to the effects of cocaine would more accurately be described as investigations of chronic rather than acute tolerance, in which a greater amount of exposure than that used in the present study was required to induce a state of tolerance over a number of days of repeated (or continuous) treatment (Hammer et al., 1997). There has been one demonstration of acute neurochemical tolerance to cocaine in rodents within a session of investigator-administered cocaine (Maisonneuve and Kreek, 1994). In that study, the exposure was substantially greater than that in the present study, both in terms of the dose administered and the longer duration associated with the intraperitoneal route of administration (Nobiletti et al., 1994). The state of tolerance we have observed occurs when there is little, although measurable, plasma cocaine remaining from the first injection. On average, the remaining cocaine was $5 \%$ of the peak levels measured 2 min after infusion (Bradberry et al., 2000).

\section{Neurochemical sensitization}

Although acute tolerance can easily be demonstrated and studied in the human laboratory, the second aspect of the present findings (i.e., neurochemical sensitization resulting from chronic selfadministration of cocaine) is more difficult to study in humans. There has been extensive work examining the neurochemical impact of chronic exposure to cocaine in the rodent (Kalivas and Duffy, 1990, 1993; Kalivas and Stewart, 1991; Segal and Kuczenski, 1992; White et al., 1995; Robinson and Kolb, 1999). Neuroadaptive processes underlying sensitization appear to involve excitatory amino acid mechanisms (Wolf, 1998; Bonci and Malenka, 1999) as well as morphological changes in neurons in brain regions involved in the mediation of psychostimulant effects (Robinson and Kolb, 1999). This is the first demonstration of neurochemical sensitization in the primate, and the first demonstration of a sensitized neurochemical response to self-administered cocaine that has been demonstrated in any species. There are reports of heightened behavioral responses to self-administered cocaine in monkeys exposed previously to psychostimulants via self-administration. In particular, they will initiate self-administration at lower unit doses (Wojnicki and Glowa, 1996). Repeated investigator administration of high doses results in progressively exaggerated behavioral responses (Post et al., 1976; Farfel et al., 1992; Castner and Goldman-Rakic, 1999). Also, there are reports of heightened behaviors and subjective reports of elevated mood with controlled repeated administration of amphetamine (Strakowski et al., 1996; Strakowski and Sax, 1998).

Because we have demonstrated previously enhanced responsiveness to cocaine in the ventromedial striatum (Bradberry et al., 2000), an issue of concern for the across-session studies is the potential introduction of a regional bias via the choice of the site order for placement. Placement order varied between medial and lateral positions as well as between dorsal ventral placements, and as can be seen in Figure 5, the distribution of ventromedial placements was not skewed toward the later studies. Also apparent in Figure 5 is the observation that sensitization did not occur in the sensorimotor striatum. This regional divergence between the sensorimotor and the mesolimbic striatum in vulnerability to sensitization has not been observed previously. However, these data (like the lack of tolerance in this region) should be interpreted cautiously because of the reduced statistical power attributable to the limited number of data points for dorsolateral striatal placement.

The incentive sensitization theory of addiction (Robinson and Berridge, 1993) presumes long-term neuroadaptations in brain regions mediating reward. The selective changes in the mesolimbic striatum that we have observed support such changes in response to intermittent low-dose exposure to cocaine in primates. This demonstration that neurochemical sensitization does occur in the nonhuman primate lends substantial support for such an occurrence in humans, as does the work of Strakowski and colleagues (Strakowski et al., 1996; Strakowski and Sax, 1998). A striking aspect of the present study is the relatively small amount of drug exposure per session as well as cumulative exposure needed to result in the progressive changes in the brain response to self-administered cocaine. Human patterns of consumption, particularly bingeing, can result in much higher levels of exposure than can the moderate ones used in this study. Thus, although the magnitude of the sensitization we observed herein was small, it remains an open question whether a more aggressive exposure to cocaine resembling human binge patterns of consumption would result in more pronounced changes.

\section{Behavioral sensitization}

The present study also leaves unanswered whether the neurochemical sensitization we observed is linked to an altered behavioral response to the cocaine cue. Although response rates from two of the animals did correlate with the time into the study, those 
animals were operating under an FR30 schedule compared with an FR10 schedule for the other two, and because they were smaller (and younger) animals, their ability to reach the lever was more awkward because of barriers to prevent them from reaching their heads. Thus, it is possible that the increased response rate over time in these animals represents increased skill via practice as well as increases because of motivational factors. It would seem that rates of lever pressing per se are not well suited for a determination of behavioral sensitization (Howell and Morse, 1989), unlike more complex primate behaviors that have been shown to sensitize in other studies (Farfel et al., 1992; Castner and Goldman-Rakic, 1999).

\section{Contribution of conditioning}

These studies also addressed the role of conditioning in the ability of self-administered cocaine to induce a dopaminergic response. Clearly, the pronounced effects of noncontingent cocaine and the lack of a conditioned response to a surprise substitution of saline suggest that the direct pharmacological effects of cocaine predominate in the dopaminergic response. Although the responses to noncontingent cocaine appear larger than those to selfadministered cocaine, it must be noted that these were the last studies conducted and that there was a hiatus in the weekly exposure to repeated cocaine before conducting these studies, conditions one would most predict to result in a sensitized response (Kalivas and Stewart, 1991).

\section{Summary}

Using a nonhuman primate model of recreational cocaine use, we observed acute tolerance to the impact of repeated infusions of self-administered cocaine on striatal extracellular DA. This may represent a neurochemical basis for the tolerance to the subjective effects of cocaine seen in humans, a phenomenon that contributes to binge patterns of consumption (Jaffe, 1990). To the extent that neurochemical sensitization may represent processes involved in the switch from recreational to obsessive consumption (Robinson and Berridge, 1993), the present results reinforce the danger of enduring change in brain function from recreational cocaine use that can put users at risk of addiction.

\section{REFERENCES}

Ambre JJ, Belknap SM, Nelson J, Ruo TI, Shin SG, Atkinson Jr A (1988) Acute tolerance to cocaine in humans. Clin Pharmacol Ther 44:1-8.

Apicella P, Ljungberg T, Scarnati E, Schultz W (1991) Responses to reward in monkey dorsal and ventral striatum. Exp Brain Res 85:491-500.

Berger B, Gaspar P, Verney C (1991) Dopaminergic innervation of the cerebral cortex: unexpected differences between rodents and primates [review]. Trends Neurosci [Erratum (1991) 14:119] 14:21-27.

Berridge KC, Robinson TE (1998) What is the role of dopamine in reward: hedonic impact, reward learning, or incentive salience? [Review; 531 references]. Brain Res Brain Res Rev 28:309-369.

Bonci A, Malenka RC (1999) Properties and plasticity of excitatory synapses on dopaminergic and GABAergic cells in the ventral tegmental area. J Neurosci 19:3723-3730.

Bradberry CW, Barrett-Larimore RL, Jatlow P, Rubino SR (2000) Impact of self-administered cocaine and cocaine cues on extracellular dopamine in mesolimbic and sensorimotor striatum in rhesus monkeys. J Neurosci 20:3874-3883.

Brauer LH, Goudie AJ, de Wit H (1997) Dopamine ligands and the stimulus effects of amphetamine: animal models versus human laboratory data [review; 112 references]. Psychopharmacology (Berl) 130:2-13.

Castner SA, Goldman-Rakic PS (1999) Long-lasting psychotomimetic consequences of repeated low-dose amphetamine exposure in rhesus monkeys. Neuropsychopharmacology 20:10-28.

De Vries TJ, Schoffelmeer AN, Binnekade R, Mulder AH, Vanderschuren LJ (1998) Drug-induced reinstatement of heroin- and cocaine-seeking behaviour following long-term extinction is associated with expression of behavioural sensitization. Eur J Neurosci 10:3565-3571.

Farfel GM, Kleven MS, Woolverton WL, Seiden LS, Perry BD (1992) Effects of repeated injections of cocaine on catecholamine receptor binding sites, dopamine transporter binding sites and behavior in rhesus monkey. Brain Res 578:235-243.

Foltin RW, Fischman MW (1991) Smoked and intravenous cocaine in humans: acute tolerance, cardiovascular and subjective effects. J Pharmacol Exp Ther 257:247-261.

Foltin RW, Fischman MW (1992) The cardiovascular and subjective effects of intravenous cocaine and morphine combinations in humans. J Pharmacol Exp Ther 261:623-632.

Glowa JR, Wojnicki FHE, Matecka D, Bacher JD, Mansbach RS, Balster RL, Rice KC (1995) Effects of dopamine reuptake inhibitors in foodand cocaine-maintained responding. I. Dependence on unit dose of cocaine. Exp Clin Psychopharmacol 3:219-231.

Haber SN, McFarland NR (1999) The concept of the ventral striatum in nonhuman primates [review; 55 references]. Ann NY Acad Sci $877: 33-48$.

Hammer Jr R, Egilmez Y, Emmett-Oglesby MW (1997) Neural mechanisms of tolerance to the effects of cocaine [review; 155 references]. Behav Brain Res 84:225-239.

Howell LL, Morse WH (1989) Behavioral effects of chronically administered cocaine in squirrel monkeys. Psychopharmacology (Berl) 97:12-16.

Jaffe JH (1990) Drug addiction and abuse. In: The pharmacological basis of therapeutics (Gilman AG, Goodman LS, Rall TW, Murad F, eds), pp 522-573. Elmsford, NY: Pergamon.

Javaid JI, Fischman MW, Schuster CR, Dekirmenjian H, Davis JM (1978) Cocaine plasma concentration: relation to physiological and subjective effects in humans. Science 202:227-228.

Kalivas PW, Duffy P (1990) Effect of acute and daily cocaine treatment on extracellular dopamine in the nucleus accumbens. Synapse 5:48-58.

Kalivas PW, Duffy P (1993) Time course of extracellular dopamine and behavioral sensitization to cocaine. I. Dopamine axon terminals. J Neurosci 13:266-275.

Kalivas PW, Stewart J (1991) Dopamine transmission in the initiation and expression of drug- and stress-induced sensitization of motor activity [review]. Brain Res Brain Res Rev 16:223-244.

Klitenick MA, DeWitte P, Kalivas PW (1992) Regulation of somatodendritic dopamine release in the ventral tegmental area by opioids and GABA: an in vivo microdialysis study. J Neurosci 12:2623-2632.

Kumor KM, Sherer MA, Gomez J, Cone E, Jaffe JH (1989) Subjective response during continuous infusion of cocaine. Pharmacol Biochem Behav 33:443-452.

London ED, Cascella NG, Wong DF, Phillips RL, Dannals RF, Links JM, Herning R, Grayson R, Jaffe JH, Wagner Jr H (1990) Cocaine-induced reduction of glucose utilization in human brain. A study using positron emission tomography and [fluorine 18]-fluorodeoxyglucose. Arch Gen Psychiatry 47:567-574.

Lynd-Balta E, Haber SN (1994) The organization of midbrain projections to the striatum in the primate: sensorimotor-related striatum versus ventral striatum. Neuroscience 59:625-640.

Lyons D, Friedman DP, Nader MA, Porrino LJ (1996) Cocaine alters cerebral metabolism within the ventral striatum and limbic cortex of monkeys. J Neurosci 16:1230-1238.

Maisonneuve IM, Kreek MJ (1994) Acute tolerance to the dopamine response induced by a binge pattern of cocaine administration in male rats-an in vivo microdialysis study. J Pharmacol Exp Ther 268:916-921.

Nobiletti JB, Jatlow PI, Bradberry CW (1994) Differences in bioavailability between cocaine and cocaethylene and their implications for drugreward studies. Psychopharmacology (Berl) 116:273-278.

Pearlson GD, Jeffery PJ, Harris GJ, Ross CA, Fischman MW, Camargo EE (1993) Correlation of acute cocaine-induced changes in local cerebral blood flow with subjective effects. Am J Psychiatry 150:495-497.

Post RM, Kopanda RT, Black KE (1976) Progressive effects of cocaine on behavior and central amine metabolism in rhesus monkeys: relationship to kindling and psychosis. Biol Psychiatry 11:403-419.

Ritz MC, Lamb RJ, Goldberg SR, Kuhar MJ (1987) Cocaine receptors on dopamine transporters are related to self-administration of cocaine. Science 237:1219-1223.

Roberts DCS, Corcoran ME, Fibiger HC (1977) On the role of ascending catecholaminergic systems in intravenous self-administration. Pharmacol Biochem Behav 6:615-620.

Robertson GS, Damsma G, Fibiger HC (1991) Characterization of dopamine release in the substantia nigra by in vivo microdialysis in freely moving rats. J Neurosci 11:2209-2216.

Robinson TE, Berridge KC (1993) The neural basis of drug craving: an incentive-sensitization theory of addiction [review]. Brain Res Brain Res Rev 18:247-291.

Robinson TE, Kolb B (1999) Alterations in the morphology of dendrites and dendritic spines in the nucleus accumbens and prefrontal cortex following repeated treatment with amphetamine or cocaine. Eur J Neurosci 11:1598-1604.

Rothman RB, Glowa JR (1995) A review of the effects of dopaminergic agents on humans, animals, and drug-seeking behavior, and its implications for medication development-focus on GBR 12909. Mol Neurobiol 11:1-19.

Russchen FT, Bakst I, Amaral DG, Price JL (1985) The amygdalostriatal projections in the monkey. An anterograde tracing study. Brain Res 329:241-257.

Schenk S, Partridge B (1997) Sensitization and tolerance in psychostimulant self-administration [review; 42 references]. Pharmacol Biochem Behav 57:543-550.

Schultz W, Apicella P, Ljungberg T (1993) Responses of monkey dopa- 
mine neurons to reward and conditioned stimuli during successive steps of learning a delayed response task. J Neurosci 13:900-913.

Segal DS, Kuczenski R (1992) Repeated cocaine administration induces behavioral sensitization and corresponding decreased extracellular dopamine responses in caudate and accumbens. Brain Res 577:351-355.

Selemon LD, Goldman-Rakic PS (1985) Longitudinal topography and interdigitation of corticostriatal projections in the rhesus monkey. J Neurosci 5:776-794.

Strakowski SM, Sax KW (1998) Progressive behavioral response to repeated D-amphetamine challenge: further evidence for sensitization in humans. Biol Psychiatry 44:1171-1177.

Strakowski SM, Sax KW, Setters MJ, Keck Jr P (1996) Enhanced response to repeated D-amphetamine challenge: evidence for behavioral sensitization in humans [see comments]. Biol Psychiatry 40:872-880.

Volkow ND, Wang GJ, Fischman MW, Foltin RW, Fowler JS, Abumrad NN, Vitkun S, Logan J, Gatley SJ, Pappas N, Hitzemann R, Shea CE (1997) Relationship between subjective effects of cocaine and dopamine transporter occupancy. Nature 386:827-830.

Ward AS, Haney M, Fischman MW, Foltin RW (1997) Binge cocaine self-administration in humans: intravenous cocaine. Psychopharmacology (Berl) 132:375-381.

White FJ, Hu XT, Zhang XF, Wolf ME (1995) Repeated administration of cocaine or amphetamine alters neuronal responses to glutamate in the mesoaccumbens dopamine system. J Pharmacol Exp Ther 273:445-454.

Wise RA, Bozarth MA (1987) A psychomotor stimulant theory of addiction [review]. Psychol Rev 94:469-492.

Wojnicki FH, Glowa JR (1996) Effects of drug history on the acquisition of responding maintained by GBR 12909 in rhesus monkeys. Psychopharmacology (Berl) 123:34-41.

Wojnicki FH, Bacher JD, Glowa JR (1994) Use of subcutaneous vascular access ports in rhesus monkeys. Lab Anim Sci 44:491-494.

Wolf ME (1998) The role of excitatory amino acids in behavioral sensitization to psychomotor stimulants [review; 406 references]. Prog Neurobiol 54:679-720.

Yeterian EH, Van Hoesen GW (1978) Cortico-striate projections in the rhesus monkey: the organization of certain cortico-caudate connections. Brain Res 139:43-63. 